Journal of

Education and Practice (JEP)

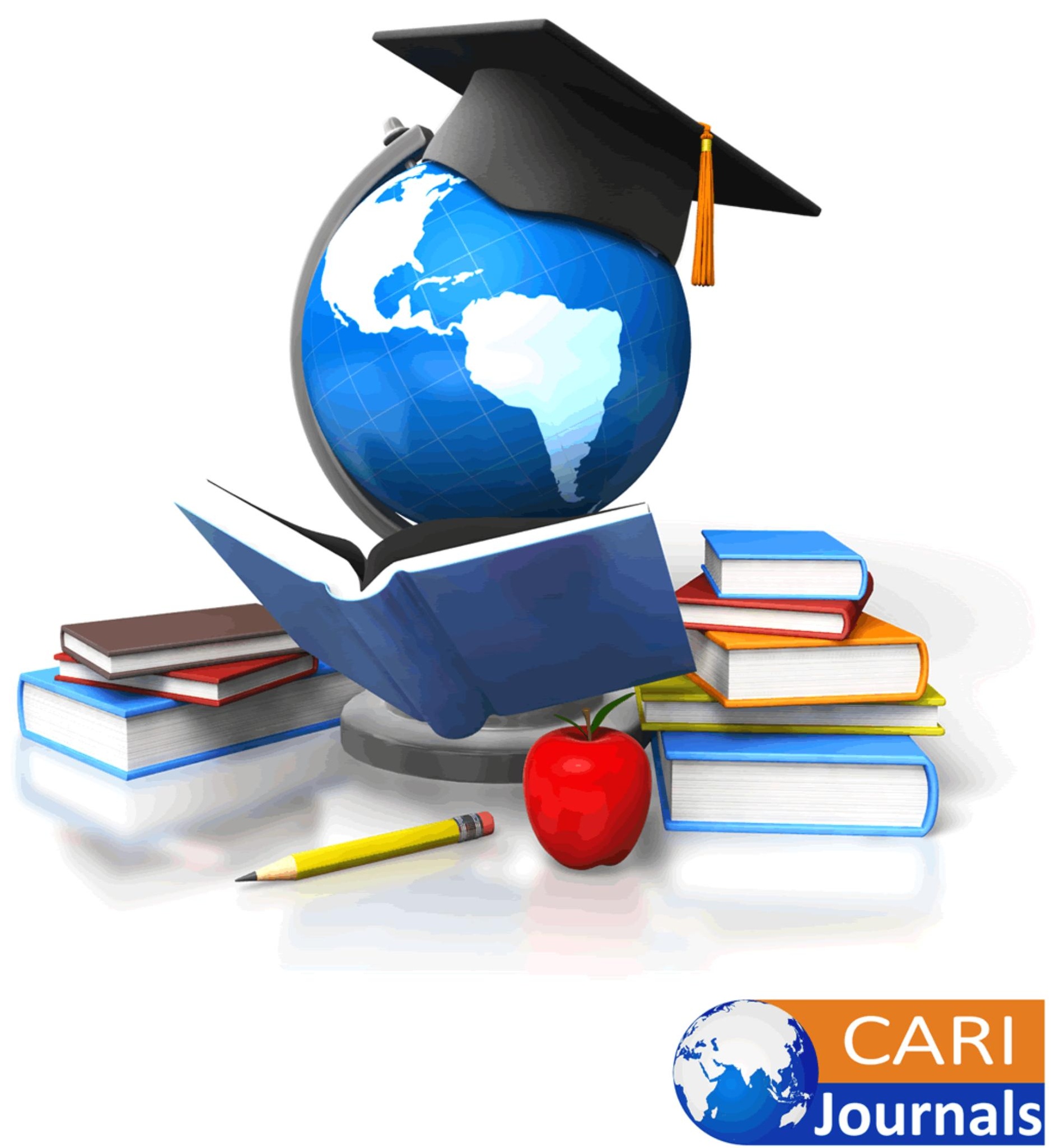




\title{
Agbacha Ekuru Nwa Dance: A Study of Performance Ethics for Music Students in Colleges of Education
}

\author{
1*Uzoma Hyacinth Nwauzor \\ Department Of Music, Federal College of Education, Okene \\ *Corresponding Author’s Email: uzor4jane@yahoo.com; hyacinthuzoma4@gmail.com
}

\begin{abstract}
Purpose: This study is an attempt to fill the gap in carrying out researches in dance performances and providing the theoretical framework for the study of general music education by students in colleges of education. To promote the baseline from which dance performance is produced to enhance cultural heritage and the structure with which all aspects of social events are finally understood. The need for increased awareness and participation in dance is apparent. In tertiary institutions, the study of dance as an academic course virtually does not exist. Dance should be given the attention it deserves in the curriculum for the promotion of sustainable development in creating jobs for the youths.
\end{abstract}

Methodology: Participant observation-adopting this survey is very necessary due to the nature of the research, it is a practical performance that involved dance groups. There are varieties of approaches to research in any field of investigation. Using the descriptive method is aimed at obtaining information concerning the current status of Agbacha ekuru nwa dance as it is expressed in the traditional setting. This is important in understanding the dance similarities among the groups selected from each of the 3 local government areas in Mbaise. The data collected for this project are obtained through oral interviews, observation, personal contact, and participation. Observation and participation in dance rehearsal are very necessary for future performance with the students. Uzoigwe (1998) explained that the descriptive method allows for better acceptance and understanding of all music elements discovered during research.

Results: Traditional dance is a part of life evolution, memory, and history, it is integral with the communities of the peoples' culture. And because communities re-shape and re-model folk music in line with changing tradition, ideals, and social interaction, it should be used to educate the people on the ills and goodwill of the society. Given the multiplicity of social performances in Nigeria, it will be possible to agree that the people's total culture is subsumed with music and dance and that it has become very important in promoting and developing our cultural heritage.

Unique contribution to theory, practice and policy: There is the need for us to revive our cultural heritage by ensuring that those subjects which teach and safeguards morals, norms and value system are given attention in school curriculum to revamp the fallen standard of education, cultural ideologies, and judgment regarding the way we see ourselves. This will lead to a drastic change in our attitude and behaviour. To better attract the interest of learners, the curriculum has a part to play; this is by designing a solid structure for the dance program in all levels of education in Nigerian schools. The nature of dance, as well as students' interest, will be captured and aimed at revitalizing general music education in our schools providing a balance between intellectual tasks and social interaction. This will be a way of expanding knowledge and skills for future use as a form of integrating cultural heritage into our 
educational system. Using Agbacha ekuru nwa dance as a case study will be beneficial to students because if all organizational principles are applied to teaching and learning it will provide structured performance ethics towards achieving collective objectives. Dance is teamwork and should be organized as such. One of the benefits is creativity in performance; talent development could be formed where students, lovers of music, and the larger society can function very well in creating dance. This will be one of the most valuable courses to enhance human personality.

Keywords: Agbacha ekuru nwa dance, music, and dance, education, performance ethnic, nature of dance

\section{BACKGROUND}

There are no better ways to explore and experience Nigeria's rich cultural heritage than joining in the colorful celebrations at every cultural festival. Traditional dance is an essential element of all aspects of the culture and life within a given community or society. It usually has functions which are conscious expressions or reflection of the structure of any society and its way of life. In all societies in Nigeria, dance is an expression of social organization in that it defines the roles the individuals, the groups within the society play. This reveals to us the pattern of behavior and thinking the people living in the same social group learn, create, and share in common; that is what we refer to as culture. Formel, Vasendova \& Stralton (2002) agree that all which makes a people distinct from others is their culture and this distinctive character includes; behavior, customs, beliefs, habits, legendary, folklores, music, arts, dance, and crafts.

There is archaeological evidence that communities have been living in Nigeria for more than 2500 years, which borders that modern Nigeria was not created until the British consolidated their colonial power over the area in 1914. The name Nigeria was suggested by British journalist; Flora Shaw in the 1890s. More than 250 ethnic tribes call present-day Nigeria their home. The 3 main and dominant ethnic groups are Hausa, Yoruba, and Igbo (pronounced ee$b o$ ). Imo state is an Igbo-speaking state with about 27 local councils bounding the landmass of the state. Each local area has its own stories, history, and ancestral linage narrating how they migrated to their present abode. Festivals and performances of social functions play prominent roles in the rituals of their daily activities like it is done or witnessed in other ethnic groups in Nigeria.

Today, Agbacha ekuru nwa dance which origins come from Mbaise has 3 local government councils in Imo state and the dance have drawn the attention of many communities surrounding it through their performances. The Mbaise people are blessed with creative tools of immense musical potentials. Interestingly dance serves as a means of recreation, pastime, and leisure to the people which help them through social gathering to ward off boredom. The women create their music after evening meals where they gather to gossip on issues bordering on family living. The children on their part engage in moonlight tales and stories accompanied by music and dance. The men from the Abigbo dance where they narrate burning issues in the community to educate the people on recent happenings. This is a people who have kept the tradition alive using dance to seek and address some social problems and to ask questions arising from their origin, practices, superstitions, beliefs, norms, and values. To these peasant farmers and petty traders, dance means everything to them and it is used to capture the essence of community life. The Agbacha ekuru nwa dance group is organized by married women. It is a group that 
brings women together which also acts as a mediator between married women and single women; it portrays the centrality of womanhood.

The group has a cultural background that had witnessed a remarkable development in the past few years. Its creativity is exemplified in investigating the peoples' culture and the dance to the benefits of the many communities which abounds in the whole of 3 Mbaise local government councils in Imo state. The performances touch on the critical nature and reflective input of dance to the history of the societies mentioned. It gives them the knowledge not only for critical analysis of facts and figures but equally in the consideration of relevant information that will promote their cultural heritage now and in the future. The result of this is in creating a new awareness of dance ethics and organization with references to different cultures in Nigeria as an internal probing for real understanding of what dance is, does with us and the purpose to which it is directed in developing the educational system and documentation of cultural heritage.

If education can influence a change in physical and mental behavior, then it must be positive to enable one to perceive accurately, think clearly, and effectively achieve self-selected goals and aspirations. The question is no longer if researches could help to give education its positive role in promoting human development, but it should be prioritized to meet the demand for qualitative and lifelong education to students. Ugobube (2016) stated that researches can be tailored towards our traditional lives and results must provide structures for students to demonstrate accessible standards in dance performances.

\section{Statement of the Study}

For 20 years this researcher taught dance in a college of education none of the students attempt to carry out a dance project. This is a problem. This has necessitated this researcher to carry out this study; not only in academics for the dissemination of knowledge but also in the application of such knowledge to creative thoughts and practical studies that will contribute to educational development to music students in tertiary institutions. This study will give students and scholars insight into knowledge information and encourage investigation on an area of interest to students. Ugolo (1994) said research is a scientific approach to problem-solving to meet the challenges of today and what is to be done in the future. This means it will give students the knowledge and opportunity to consider with relevant information how to research and make input to the organization of dance.

\section{Purpose of the Study}

The study is an attempt to bridge the gap which exists in dance performances and provide the theoretical framework for the study of general music in colleges of education in Nigeria. And to contribute further understanding of the products and processes in traditional man's life; and precisely because is simply another element in the complexity of individuals learned behavior. And to promote the baseline from which dance performances are produced to enhance cultural heritage and the structure with which all aspects of social events are processed and finally understood.

\section{Scope of the Study}

Particularly interesting in this study is the area of coverage, and for the research, 3 local government councils within Mbaise will be the focus and 3 federal colleges of education; 
Journal of Education and Practice

ISSN 2520-467X (Online)

Vol. 5, Issue No. 1, pp 70- 82, 2021

$\underline{\text { www.carijournals.org }}$

naming FCE, Okene, FCE, Eha-Amufu and FCE, Panskish. This is because much of the music and dance performed in these areas and colleges share a close affinity.

\section{RESEARCH METHODOLOGY}

Participant observation-adopting this survey is very necessary due to the nature of the research, it is a practical performance that involved dance groups. There are varieties of approaches to research in any field of investigation. Using the descriptive method is aimed at obtaining information concerning the current status of Agbacha ekuru nwa dance as it is expressed in the traditional setting. This is important in understanding the dance similarities among the groups selected from each of the 3 local government areas in Mbaise. The data collected for this project are obtained through oral interviews, observation, personal contact, and participation. Observation and participation in dance rehearsal are very necessary for future performance with the students. Uzoigwe (1998) explained that the descriptive method allows for better acceptance and understanding of all music elements discovered during research.

\section{THE EMPIRICAL LITERATURE ON THE ORGANIZATION OF DANCE AND STRATEGIES TO BE FOLLOWED IN A DANCE RESEARCH PROJECT}

Music education is a field of study which is involved with the teaching and learning of general music. Interestingly, it leads to the study of all other aspects of music including having some form of talent and creativity in dance. It is a course in some tertiary institutions that provides students with critical knowledge and skills leading to the invention of problem-solving in education. The unified course content in colleges of education in Nigeria where music is taught reflects on the goals and objectives in education for all. Uzoma (2015) said music education trains students not only in the acquisition of general music knowledge but also in developing potentials and skills for wealth generation. This is in line with the philosophy of music education as contained in the minimum standard of colleges of education (NCCE 2012). Dance as expected is a meaningful art form that is closer to the traditional and musical culture of many societies in Nigeria today. It could be traced to the creation of mankind and presently it functions adequately in music performances. It has brought to us new concepts of ideas, values, application, and attitude towards the development of the mind and the societies we live in. This is seen when given the time, rhythm, space, and other musical elements to enhance an appropriate release of emotion. Agbacha ekuru nwa is a musical experience that should be investigated because it reveals a lot about people's way of life during performances.

The performance ethics of Agbacha ekuru nwa is a facilitating creativity practice, sequencing a learning process, appropriately provided to give the visible source of information towards promoting learning experiences. It has been discovered; according to Sophia (2007) that dances are a functional, practical, and innovative tool to promote knowledge while creativity is another benefit to be derived by the study when exposed to performances. It will be a process of improving the array of opportunities available to students to discover their potentials over some time. We must accept the fact that time has changed and new ideas need to be brought into the classroom to prepare learners for life after school.

\section{Meaning and nature of dance}

In modern times, education continues to witness a growing desire for traditional recognition in individuals and groups search for identity and a conscious exhibition of distinctive cultural 
traits. In Agbacha ekuru nwa, it is an attempt to showcase a traditional experience occurring in the context of dance performance. The dance prepares communicative scenery for the manifestation of cultural unity with a special objective to demonstrate and express a particular identity. To Stoeltje (1992) dance is a performance that serves the purpose in the articulation of groups' heritage; it is a communicative situation actively engaging participants while presenting a combination of performance and drama in a public context.

The Agbacha ekuru nwa dance of Mbaise societies is a large-scale, extravagant cultural performance with dialogue that is situated at a wider and general communicative level. It is the performance that is anchored on belief and as story women tell themselves-"a gossip". Dance plays a key role in developing cultural awareness and heritage. Apart from this, their physical aspect in rhythmic movements, steps, and mood or emotions illustrates specific events in the community's experience in recounting history.

\section{Performance ethics}

Once a group is identified, areas to be looked into are the people's musical tradition and ownership. If the group selected is owned by a community; then the researcher must make consultations through field assistants or contact persons. The idea and concept of a musical ensemble are that which is influenced not only by its traditional framework or linguistic background but by the extension of activities with which it is prescribed. In normal events, the context of performance determines the time there is, drama, social relationship with other arts, belief, communal occasions it is performed leading to cultural understanding. Because most events celebrated are prescribed by tradition, it is used to connect the people to their history and mandate for a collective observance during the celebration. Researchers must look out for this especially that involving religious festival which showcases feelings and experiences that may be very deep-rooted in tradition. For the people, musical and dance performances are owned by the community and must abide by the rules and regulations that conform to the wellbeing of all members of the society.

From here, the researcher must take cognizance of traditional adherence to the principles of what is expected as norms within the chosen group and also all the villages and communities which abound in Mbaise. The researcher will make use of field attendants for contacts, interviews, and arrangements during rehearsals and performances. This is because the transmission of dance is learned through observation and participation. Interviews are necessary to gather data and more information about the group.

\section{Organization of dance}

Traditional dance here can be another term for folk dance or sometimes even for ceremonial. Dance, Enekwe (1991) said that its beauty lies in the combination of purposeful and aesthetic concern, its celebration, and reflection on communal life and virtue. And so the expressive characteristic of traditional dance makes it a very vital tool for communication in society. The Agbacha ekuru nwa dance in Amuzu that forms part of the many communities in Aboh Mbaise has promoted dance to the forefront of traditional settings. The women from this community cannot do without music and dance, and one of the most important attributes of music is that; it is not only to be listened to but also to be danced. This follows with the belief of Amuzu people whose instrument for cultural development is dance. To distinguish between the varieties of dance styles, therefore, it is necessary to establish the purpose for which Agbacha ekuru nwa dance is performed. It must be noted here, that the more significant the concept 
expressed in a dance, the greater the appreciation of the audience and the more insistent their demand for a skillful performance and for the movement that fits its purpose. Onwuekwe (2005) observed that dance performance provides an accessible standard towards traditional education for better structure in promoting togetherness. Dance has been used by communities who embrace it as a tool for continued existence, preservation, and reminder of its traditional values and development to cultural heritage. Its formation and organization are based on the following:

\section{Membership}

Agbacha ekuru nwa group is exclusively for married women and dancers who come together with the common interest to project the centrality of womanhood. It is a voluntary organization that accepts women who are committed to contributing their quota to build a united front in establishing family structure within the society. Qualification for membership is strictly for married women who have proven to be of good character with impeccable integrity. The community can vouch for them and as a quick reminder that what the dance stands for; is what the members represent in the society. The position of the group is clear, that it is only when people accept responsibility for their social and material conditions that they can embark on a meaningful search for appropriate solutions to problems. Afam (2012) said dance performance contributes to the understanding of the traditional man's past experiences. This is precisely why dance is simply another element in the complexity of individuals' learned behaviour. Apart from interest, members are expected to be good dancers, have good voice quality, law-abiding, respect rules and regulations guiding the group, and be able to project the activities of the group to the public. Some of the rules come in line with rehearsals, meetings, contributions (dues and levies) and discipline, group solidarity at times of fortune or crisis, and finally attendance to occasion for performance. As a prescription of tradition, every member of the community is a participant in the group as non-registered members can also take part during the performance of the group because the dance is collectively owned by the community. Members of the community are allowed to participate in the performance as a mark of appreciation especially when one goes out to give or spray money.

\section{Rehearsals}

In every community in Igbo land, whether it is a simple or complex one, the organization of a dance group is usually as paramount as in setting up everything especially when it has to do with entertainment. Rehearsal for the group is as important as performance proper, everything is put in place to achieve perfection during rehearsal which comes twice a week or regularly when there are new songs and dance steps to be learned. During rehearsals, there is room for contributions especially when learning new dance steps are introduced to the group. This is collectively learned featuring dance movements, styles, and variations.

For stylized dance movements, the rate and sequence of the change of choreographic variation are well-rehearsed and internalized by dancers. Here, dance sequences and movements to be followed by dancers usually carry varying uniformity during performance giving aesthetic considerations. This is because every choreographic movement must be followed to the letter otherwise the dancer may mislead others and this is most often corrected through long hours of rehearsal. Movements are the product of the fallout of the development of the dance storylines, with a structured variation derived from dance performances. 
Sometimes, when a dance is to be borrowed, experts are invited to teach them the dance steps and the accompanying songs which are incorporated to make for a well-organized performance. As a rule, dance practices stress participation and observation which makes it mandatory for members to be present at every rehearsal. Members derive self-confidence, discipline, and commitment to the communal arrangement.

\section{Dance Movements}

Movements and dance patterns structured into styles vary greatly from one culture to another, depending upon how environmental, historical and social situation plays its roles. People living within the earth structure like Amuzu people with the open and level ground where the land is hard to tend to dance with agility and stamping of the feet while those who live along the riverine or coastline dance with their waistline bent showing a wriggling effect like a fish.

For Agbacha ekuru nwa dance, it is usually a slow tempo at the beginning, which increases as the dance progress, performing a simple foot pattern at a steady movement following the dictate of the lead dancer and dialogue through drum language from the master instrumentalist. The lead dancer displays an articulated dance structure which is accompanied by music. A common feature in the dance movement is that of a subtle and expressive thought exhibited with ideas and ecstasy from inner feelings appreciating the rhythmic flow of music. The bent knees are used for alertness and readiness to pick the forth and back ( 2 steps forward and 2 backward) movements with the expectation when the lead dancer will blow the whistle for a crescendo in rhythm attracting dancers for fast dance movement and variations in a sequenced dance. Most often the blowing of the whistle with fast dancing may lead to the end of the dance, while in other times, it may be an avenue to introduce a new dance.

\section{Dance Formation}

In dance formation, the dancers use a free formalized structure which allows for earthbound patterns to attract audience participation and to the admiration of spectators. There is also the circular formation which gives a continuous dance sequence during the performance. This, they have taken knowledge of, which encourages the solo dancer to have an occasional dialogue; where the master drummer can extemporize while the solo dancer interprets. The circular formation is an agreed one where the musicians are surrounded by dancers to get a better view of the ensemble. This is symbolic, but because the dance does not only evoke the emotion of dancers it also reflects on the relevance of the culture dealing with situations that concerns every member of the community using dance. In most cases, the performance is stage has drawn; where body movements, posture, and facial gestures and expressions tell specific stories. Here again, the performance gives the audience an opportunity of finding out how dance has sustained the cultural belief of the people. It tries to mirror the challenges that had faced true traditional situations which are presented in their music and dance.

\section{Instruments and accompanying roles}

Abacha ekuru nwa is a graceful dance with incredible body movements; it is a dance for suppleness, peace, togetherness, unity, beauty, and the building of a stable home. It is grounded in a complex drum rhythm and other accompanying instruments in the ensemble where only trained dancers can expertly perform in a way that truly represents the tradition and wellbeing of the people. The body movements represent a holist view of what life means to the people and the code of conduct that is enshrined in the community's daily experiences. Today, the 
group's performances are purely symbolic to show collective responsibilities to the development of Aтиzи- Nweafor Autonomous community in Aboh Mbaise local government council in Imo state and their triumph over communal challenges.

A master instrumentalist is a man who plays the drum called Oke nkwa (masculine or male drum); he uses it to dictate the rhythmic pattern of all dance movements. Incidentally, the oke $n k w a$ is small in size; it plays the leading role in the ensemble while Nne $n k w a$ is bigger and plays a subsidiary or accompanying role. Reasons, why the Oke nkwa plays the leading role or coordinating role, is because it can be used to improvise or extemporize at will; depending on the expertise of the master drummer, he directs the range or duration of the dance. He selects old songs from their repertoire and introduces them to new songs. He can equally stop the dance in the middle of the performance, corrects mistakes without audiences comprehending what had gone wrong, and also when he wants a dialogue with the solo dancer. Other instruments play subsidiary roles and what is important here is, the drums are named along the family line. The Nne nkwa (big drum-mother) accompanies other drums, there are other percussive instruments very common with the group which enhances the effects and quality of good performance. The slit drum (ekwe) a log of wood hollowed out on one side and played with sticks. Rattles (Osha), pot drum (udu), and bells (alo or ogene) are equally used in the ensemble. The rattle is very common in most Igbo women dance groups because they can easily play them for rattling effect during music-making events. The bells maintain the time liner on any piece of music played. During this research, it was observed that women could hardly play drums due to it technicality of play, that women do not have a good sense of rhythm, this is yet to be proven right.

\section{Leadership Role}

The Agbacha ekuru nwa group is very concerned about promoting orderliness within its organization. Whatever affairs played out during and after each rehearsal and performance should adequately be accounted for. From the fallout in its organization, certain roles and duties are given to some individuals to oversee. These offices are created to ensure that there is discipline and with well-coordinated officers, the structure of the group is kept in check. The sponsor or matron of the group is given to an elderly woman or retiree of the group who must have been a member till old age and can no longer participate actively in their outings and meetings. Her duties will be to settle scores, advisory role during disputes, financial misunderstandings within and outside engagements. She is known as Nne Egwu (Mother of the group). Leaders are selected based on skills, organizing abilities, and creative flair. The lead dancer must be a good dancer and have the ability to control others and the charisma to lead; directs and teaches other dancers new dance steps and movements. She must be able to interpret drum commands and carry out a dialogue with the master when the need arises. The master instrumentalist can coordinate other musicians in the ensemble; he equally assigns roles to other instruments. Not only that; he repairs, preserves, and keeps in custody all the instruments. During the performance, he can improvise and extemporize or call for dialogue with a solo dancer to extend the duration of a performance.

\section{Rules and regulations}

Culture is indeed an aspect or factor which helps to determine the acceptability of what kind of music is suitable for each community. It also explains the principles which guide and frame its sustainability within such people who claim ownership of any group of musical elements. 
When this is organized, some rules and regulations guide each group and member. Each member is expected to conform to what tradition prescribes. As the representatives of the community, the set aside rules must be followed. That each member must obey constituted authority, in-house quarrels must not be allowed, fighting of any form must be discouraged, committing abominable offense attracts capital punishment. Taboo is an offense under the code of conduct of tradition and must be frown at. Each member must represent the interest of the community in terms of promoting the beliefs, aspirations, myth, behaviour, norms, and values using dance to educate the people.

This can be achieved when dancing responds to societal needs and its involvement in the collective social order. When a group project the image of the society, it gives meaning to the moral organization to the people. All these include knowledge, class status, qualification as an ambassador of the community, obligation expected by tradition, laws to be obeyed, ideals, and respect for one another. If all these exist in the framework of the dance group then it will help to interpret, frame, and shape the values in it. From here the society will be accountable for the pitfalls that come if things go wrong.

\section{Analysis of findings}

The urge to dance and watch others dance is deeply rooted in our cultures. For many centuries, dancing has been vital to human life. Dancing to the traditional man is a respectable experience and it is the opinion of scholars that it should be taught and learned in our schools because it has worldwide educational values and it is a more meaningful avenue in perpetuating and transmitting the culture from one generation to another. However, dance and its development have continued to struggle out of sympathy and relevance with music education and creative arts where it is studied.

In schools or at most tertiary institutions, the study of dance as an academic course virtually does not exist. Where it exists at all, it is used to complement other courses e.g. department of Performing arts, the University of Ilorin in Kwara state, and other universities with Theatre arts. For colleges of education, it is a one-unit course outside music. To say you are studying dance is looked upon as something unimaginable. This is because, in traditional societies, it is believed that everybody is gifted to dance. It is one of the courses outlined or stipulated in the minimum standard for music education by NCCE. The three colleges of education used as a survey are currently teaching dance elements and choreography. However, dance project by students is absent due to lack of interest and exposure. The students cannot make any meaningful research on traditional dances within their community as a result of a lack of materials.

With regards to this, it is rather difficult for students to embark on any meaningful researches because of a lack of resource materials e.g. books, journals, and articles. Without researches on dance, materials would not be available for students to make use of, this is discouraging. The proper methodology is not there for students to follow and currently, the course is being considered to be removed from the minimum standard (NCCE). If this is done, then the tradition and cultural heritage in most societies will be eroded.

Problems which seem to erode the documentation, application, and performance of dances in many cultural settings are modern and religious. Some recordings of dances that are still performed today seem to be losing their original forms, aesthetic values, the standard of excellence, and the ideals upon which they are presented. This is because some dances and 
their ownership have met with strong opposition or that people are no longer interested in our dances. Reasons for these are not far-fetched.

Christianity is one of the greatest opposition to dances based on the current belief that getting involved in traditional dances is related to idol-worshipping which is against the doctrine of Christianity. That dances related to deities and the worship of gods, and participating in events connected with ancestral linage should be discouraged. Christianity discourages the show of affinity to the worship of idols, gods, and ancestral spirits, i.e. Mmanwu (spirit). All dances within these categories are gradually going extinct and wherever they still exist, members are seen and regarded as devotees to the cult or secret society groups.

Masquerading in Igbo culture involves sacrifices, rituals, and acquiring of occult power; which is sought by members to make them relevant. Mmanwu is a traditional masquerade that attracts few individuals as members and is seen as people belonging to cult due to the sacrifices they perform at the shrines of deities. Their activities are accompanied by dances especially with those who have masquerades. Again, masquerades in most Igbo communities are regarded as spirit manifest; they embody the spirit of gods as such there is a connection to them through communion and consultation made to appease deities. For this to take place, masquerades which inhibit evil spirit are expected to act as a link or bond communicating with the gods. During performances, the masked display various dramatic activities with speeches and dialogue. Because of this, traditional dances are gradually being faced out in the social context of most communities.

Modern traits- this is another factor that has brought a lack of interest among the people. Before the spread of Christianity, most societies in Nigeria believed in a complex structure of spirits and ancestors who influenced their living. As a result of this, cultural dances were performed in line with their activities for the wellbeing of the people. The structure and body movements depicted the way such spirits relate with the people coupled with rituals or sacrifices to deities.

In every culture, there are certain ideals explicit in the interaction of different elements for social control with which different cultural segments are held together. When modern reasons iterated, people began to look the other way regarding the kind of dance events to be watched and what are the materials involved in meeting with demands of the society. Gradually they discovered that some of the occasions for music-making experiences are no longer necessary as this appears to represent the wicked ways of the gods who demand blood for sacrifices to appease them. People began to get less interested considering the consequences to the development of society.

\section{Organization of dance performances in-school program}

The following can be derived from teaching and learning dance.

a) Dance performances in the higher institution have experienced certain changes in content and identity in Nigeria where it is taught. Indeed, the content upon which it is taught in the three colleges of education used as survey namely FCE, Pankish, FCE, Eha-Amufu and FCE, Okene; do not give it a place where students can academically embark on research. It is equally true that the curriculum has the largest portion to play here because it must be meaningful and appropriate for learners. Dance should be an experience that 
can contribute significantly to the overall development of learners in terms of emotion, talent, aesthetic performance, and the promotion of cultural heritage. It should be an integral part of the course content in general music education as stipulated by NCCE minimum guidelines. Patrick (2002) explained that two major goals can be derived from today's educational pursuit. That performance on dance should be well structured to meet the needs of learners and teach towards a positive achievement level for them to develop a greater attitude for lifelong educational development.

b) In the school setting, dance appears in various forms; folk, creative, traditional, and modern. Young (2003) stated that dance education could be used to provide opportunities to students for the development of analytical skills, potentials, critical thinking, teamwork, self-expression, and communicative reasoning. Dance study in colleges of education in Nigeria will benefit students and support cultural learning goals and also provide innovations to them. This approach will enable them to carry out investigative researches on their own. They can acquire information from archives and recordings through media technology information systems with exploratory ways to research people's culture relating to dance performances. Here, students will be provided with valuable and creative tools such as videos, multimedia gadgets which will enhance learning by watching documented information on people and their dance culture.

c) In addition to this, the new technology can help students with dance teachers to reach out on online communication to learn more about other people's ethics to dance presentations. This will help to document and assess their learning; keeping journal articles and elements of dance for future use. Akas (2014) said this new method can be used in the dissemination and learning of traditional dances. For example, the Agbacha ekuru nwa group could be used as a resource material in teaching dance performances through a recorded platform to students.

d) From my experience over the years as a teacher in a college of education, none of my students got interested in research for any traditional dance. In the course of our dance study, they showed excitement and interest in getting involved with performances solely to pass the course. They saw each rehearsal as teamwork and learning of body movements/skills as well as acquiring knowledge about history, interactive sessions, and group solidarity. It revealed to them that the nature of dance is an integral part of their cultural life reminding them of their background and experiences. To this end, greater efforts should be made to promote the study of dance in schools to keep our heritage intact; this is because dance plays a veritable role in the history of a people.

\section{What students will benefit from dance study?}

- Dances are known through historical events that happened in the past. The more learners are exposed to these events, the better knowing they will be with people's cultural heritage which abounds in many societies in Nigeria today.

- Dance should be seen as a career or wealth generation for the youths these days; this is because there are opportunities in the music industry and creative arts where their talents are generating money for them. Musicians are engaging them during performances and video recording.

- Dance as a motivational and building activity for learners for specific benefits in health, stress reduction ability, and long life spectrum in creativity to music. 


\section{Conclusion}

Traditional dance is a part of life evolution, memory, and history, it is integral with the communities of the peoples' culture. And because communities re-shape and re-model folk music in line with changing tradition, ideals, and social interaction, it should be used to educate the people on the ills and goodwill of the society. Given the multiplicity of social performances in Nigeria, it will be possible to agree that the people's total culture is subsumed with music and dance and that it has become very important in promoting and developing our cultural heritage. Ojuade (2006) agrees that these cultural demands cannot exist outside the control and behavior of the people. The study of dance in our schools will certainly help in the continuity of our tradition, beliefs, and value system. If then the question is asked today, how has dance been used to transform the socio-cultural needs of the people? The answer will be; that dance has been a unifying factor in achieving a great deal of transformation, improving on the living conditions of the people, transmitting the right cultural values, modifying existing laws, tradition and in the maintenance of peace and social order when music elements are presented for cultural communion.

\section{Recommendations}

Since there is a growing need for continuity in our traditional dances in Nigeria, the results from this study may be a valuable means of appreciating the effort of using Agbacha ekuru $n w a$ dance group as a case study to prepare the minds of students of music on how to carry out research projects. The following is therefore recommended for the future of music education.

- There is the need for us to revive our cultural heritage by ensuring that those subjects which teach and safeguards morals, norms and value system are given attention in school curriculum to revamp the fallen standard of education, cultural ideologies, and judgment regarding the way we see ourselves. This will lead to a drastic change in our attitude and behavior.

- To better attract the interest of learners, the curriculum has a part to play; this is by designing a solid structure for the dance program in all levels of education in Nigerian schools. The nature of dance, as well as students' interest, will be captured and aimed at revitalizing general music education in our schools providing a balance between intellectual tasks and social interaction. This will be a way of expanding knowledge and skills for future use as a form of integrating cultural heritage into our educational system.

- Using Agbacha ekuru nwa dance as a case study will be beneficial to students because if all organizational principles are applied to teaching and learning it will provide structured performance ethics towards achieving collective objectives. Dance is teamwork and should be organized as such. One of the benefits is creativity in performance; talent development could be formed where students, lovers of music, and the larger society can function very well in creating dance. This will be one of the most valuable courses to enhance human personality.

\section{REFERENCES}

Adegbite, A (2010). The impact of African traditional dance: Ovosun example. Journal Media and Communication Studies. 2, 6. 133-137. 
Journal of Education and Practice

ISSN 2520-467X (Online)

Vol. 5, Issue No. 1, pp 70- 82, 2021

www.carijournals.org

Afam, E (2012). Expressing indigenous knowledge through dance. African journal of history and culture. 4, 5. 66-73

Akas, N.C (2014). The potentials of Ekeleke dance performance as a tourist attraction. Arts and design studios. 25 39-46

Enekwe, O (1991). Theories of dances in Nigeria: An introduction. Nsukka. Afa Press.

Federal Government of Nigeria (2012). NCCE Minimum Standard. Abuja: Tetfund

Formel, K, Vasendova, J \& Stralton, G (2002). Dance as a fitness activity: The impact of teaching style and dance forms. Journal of Physical Education, Recreation and Dance. $75,5.26-30$

Ikibe, S. O (2014). The impact of slavery and colonialism on African traditional music and dance performances. A journal of Theatre and Media Studies. 8, 2. 144-162.

Ojuade, J. (2006). Dance culture and development in Nigeria. A case study of Gese dance of the Yorubas. Presented at the $20^{\text {th }}$ world Congress on dance research. Athens: Greece.

Onwuekwe, A.I (2009). The social-cultural implication of African music and dance. www.ajol.info.view pdf.

Patrick, A (2015). Two tips on how to write the significance of a study. In a simple educate me. Retrieved from http://simplyeducateme//2015/02/09/two-tip-on-how-to-write-thesignificance-of-a-study.

Sophia, B, Evangella K, Vicky K \& Maroussa (2007). Teaching traditional using e-learning tool. https://www.researchgate.net

Young, O (2003). Status of dance in Education. Eric digest. Retrieved from http://ericae.net/db/edo/ed348368.htm.

Stoeltge, B.J (1992). Ritual, Folk, cultural performance, and popular entertainments. (ed). Richard Bauman. New York.

Ugobube, F. (2016). Nigerian traditional dances you should know. Retrieved from https://omgvoice.com/lifestyle/nigeria-traditional-dances

Ugolo, C.E (1994). The state of dance research in Nigeria. Dance Research Journal. Published by Congress on Research in Dance. http://www.jotor.org/stable/1477938.

Uzoigwe, J. (1998). Ukom: A study of African Musical Craftsmanship. Okigwe: Fasman Communication.

Uzoma, H.N. (2015). Transformation in education and sustainable development emerging issues in music education. International Journal on Contemporary Issues. 3, 2. 184192. 